\title{
Burnout and Related Factors Amongst Special School Teachers in Samarinda
}

\author{
Iwan M. Ramdan \\ Health and Safety Department, Faculty of \\ Public Health \\ Mulawarman University \\ Indonesia \\ iwanmuhamadramdan@gmail.com
}

\author{
Effidiyanti Yasinta \\ Faculty of Public Health \\ Mulawarman University \\ Indonesia \\ Effidiyantiyasinta@gmail.com
}

\author{
Bibit Suhatmady \\ English Department, Faculty of Teacher \\ Training and Education \\ Mulawarman University \\ Indonesia \\ Suhatmady@yahoo.com
}

\begin{abstract}
Special school teachers are vulnerable to burnout, but research of burnout on this profession has not revealed much. The purpose of this study is to investigates the burnout of special school teachers and to analyze related factors. Crosssectional studies were conducted on 90 teachers in the city of Samarinda. Determining sample size using Slovin's formula, data were assessed using the Maslach burnout inventory, a depression anxiety stress scale, and the Tennessee self-concept scale. Data analysis used chi-square and Pearson correlation. All of the teachers had experienced burnout $(26.7 \%$ low level and $73.3 \%$ medium level). Marital status $(p=0.034)$, working experience $(\mathrm{p}=\mathbf{0 . 0 2 3})$, hours of teaching $(\mathrm{p}=\mathbf{0 . 0 4 4})$, self-concept $(p=0.010)$ and job stress $(p=0.004)$ correlated significantly with burnout. It was concluded that burnout amongst special school teachers requires immediate treatment. The school is advised to reduce the teacher's workload, make efforts to improve teacher self-concept and provide training for beginner teachers on educating students with special needs. For further research, it is advisable to further explore the factors causing job stress on the teacher so that the appropriate alternative can be found.
\end{abstract}

Keywords: burnout, special school, self-concept, job stress, demographics

\section{INTRODUCTION}

One of the basic components for achieving education goals is the teacher through his very important and strategic role. The quality of education is largely determined by teacher performance. One factor that often causes a decrease in teacher performance is burnout due to prolonged work stress [1,2]. Burnout is defined as emotional exhaustion, depersonalization and reduced personal accomplishment [3]. Burnout is a matter of occupational health and work productivity with an increasing prevalence in various occupations, including the human service professions.

Job burnout costs organizations on many levels including frequent job changes, turnovers and reduced work performance quality [4], increased accidents [5], increase work absence [6], and decrease in job satisfaction [7,8].

The incidence of burnout in teachers around the world is quite high. The estimated prevalence of burnout in teachers can be situated between $10 \%$ and $30 \%$ [9], while that both in the Western countries and in some Eastern European countries, about $10-40 \%$ of teachers suffer from burnout, while in Asian countries it may reach $50-70 \%$ [10]. Due to burnout, two-thirds of new teachers will leave the job within 4 years and over half of them will leave within 7 years, 20 $30 \%$ of beginning teachers will leave the career in the first 3 years [11].
In the case of those who teach in regular schools, research on burnout has been widely conducted. Among the conclusions reached is that the prevalence of burnout is quite high and is influenced by various factors such as sex, age, location of the school, self-efficacy, work experience, workload, and educational levels $[6,9,10]$. Others result concluded teachers' self-concept correlates with burnout [14], level of burnout for teachers in private institutes employed is higher than that for public institute teachers, work experience is associated with emotional exhaustion [15], work stress has a significant relationship with emotional exhaustion, depersonalization, and personal accomplishment [16], job stress and burnout correlated with job satisfaction [17]. However, studies that uncover burnout on these special school teachers have not been widely conducted.

Special school teachers are vulnerable to burnout because of the different role than general education teachers. The complex roles fulfilled by special education teachers, including utilizing professionally recognized best practices for instruction, management, and assessment, knowing each individual student's strengths and challenges, advocating for students, and collaborating with families and other education professionals involved with students' instructional teams [18]. The special education teachers are chronically faced with the arduous task of maintaining students' discipline amid fears of physical and verbal abuse [19]. Special education teachers are well known for their high-quality work loads.

This study aimed to analyze the prevalence of burnout in teachers who teach at special schools in the city of Samarinda, Indonesia? And what factors influence it?

\section{METHOD}

\section{A. Design of The Study}

A cross-sectional study was conducted at Special Schools located in Samarinda, East Kalimantan province of Indonesia. The independent variables consisted of teacher demographics (age, gender, marital status, educational background, employment status and working experience), workload based on teaching hours, job stress and self-concept. While the dependent variable is burnout.

\section{B. Population and Samples}

The population of special school teachers in Samarinda City is 112 people, spread in 11 schools. Based on the Slovin formula's [20], the sample size for the study was 90 teachers. The sampling technique used in this study was a proportionate stratified random sampling [21]. 


\section{Instrument and Procedures}

To collect teacher demographic data (age, gender, marital status, educational background, employment status, working experience, and length of teaching hour per week) a questionnaire was used. The Maslach burnout inventoryhuman service survey (MBI-HSS) was used to measure burnout. The MBI-HSS consists of 22 statement items: statements numbered $1,2,7,8,14,15,19,20,22$ for emotional exhaustion; statements numbered 3, 4, 9, 10, 16 for depersonalization, and statements 5, 6, 11, 12, 13, 17, 18, 21 for low personal accomplishment [22].

The Tennessee self-concept scale (TSCS) was used to assess teachers self-concept. TSCS was developed by Fitts and Warren in 1996 as a valid and standardized scale to measure multi-facets of self-concept, and it comprises 36 items. It is an extensively used scale to assess the general perception of an individual about him/herself. Each item is rated on a 5 point Likert scale ranging from $(1)=$ Not true at all to $(5)=$ Very true. A high score represents positive selfconcept whereas low score is representative of negative selfconcept. To measure personal, social and family self-concept of adolescents, the scale has three subscales [23].

The depression anxiety stress scale 42 (DASS 42) was used to measure teacher job stress. DASS is a set of subjective scales established to measure the negative emotional states of depression, anxiety, and stress. DASS 42 is formed not only to measure emotional status but for understanding and measuring any emotional states typically described as stress. The stress levels measured by this instrument are normal, light, moderate, heavy and very heavy. DASS 42 consists of 42 items, which include 3 subvariables, that is physically in accordance with statements numbered 2, 4, 7, 12, 15, 19, 23, 25, 41; emotion / psychology at statements numbered $1,6,9,10,11,13,18$, $20,26,27,33,36,37,39,40$ and behavior at statements numbered $3,5,8,14,16,17,21,22,24,31,34,35,38,42$ [24].

\section{Data Analysis}

A descriptive analysis, including frequencies and percentages was generated. Pearson product-moment was applied to analyze the correlation between burnout and independent variables (age, working experience, hours of teaching, job stress and self-concept), while the relationship between burnout and gender, marital status, education background, and employment status was analyzed using Chisquare.

\section{RESULTS AND DISCUSSION}

Most teachers are in the age-groups 46-54 and 37-45 years with percentages of 37.7 and 24.4 respectively. Most of the special school teachers are female $(78.9 \%)$, and married $(81.1 \%)$. Non-special school education is the dominant teaching background of the teachers $(78.8 \%)$, with work experience of $0-8$ years $(34.4 \%)$ being the largest category, while $80 \%$ of teachers give their employment status as permanent workers, and most teach 24 hours per week (90\%). All the special school teachers in Samarinda reported experiencing burnout $(73.3 \%$ medium level and $26.7 \%$ low level). Positive self-concept was reported by 45 people (50\%) and negative self-concept by 45 people also (50\%). Most teachers do not experience job stress; only 27 teacher (20.1\%) experienced light work stress (see table 1). The highest levels of burnout experienced by special school teachers occurred in the dimensions of emotional exhaustion and personal accomplishment (table 2).

\section{A. Burnout prevalence of special school teachers}

All the special school teachers in Samarinda experienced burnout. The results of this study prove that in special school teachers, incidence of burnout is higher than is the case with teachers teaching in regular schools in various countries $[11,10,12,22,23,24,25,26]$.

\section{B. Burnout and Marital Status}

The results showed there was a significant correlation of marital status and burnout at the special schools teacher. This result is consistent with previous research which concludes there is a relationship of sex and marital status with burnout amongst teachers in Indian Punjab [29], marital status is related to burnout in the depersonalization dimension among education professionals working with people with disabilities in Córdoba (Spain) [30]. According to Ogden [31], single status individuals have a higher risk of experiencing burnout than those who have a partner. For those who are single, the absence of a partner reduces the chances of getting support when faced with a problem. In the case of those who are married, the spouse is the person who is seen to be the most supportive when dealing with problems. Nevertheless, the results of this study contradict previous research which concluded that marital status was not related to burnout in education professionals who work with people with disabilities [30, 31, 32].

\section{Burnout and Work Experience}

We found length of work experience to be significantly related to burnout. These results are in line with previous research which concluded work experience is significantly related to burnout amongst the administrative staff of the Kermanshah University of Medical Sciences of Iran [6], amongst Iranian English language educators [15], amongst teacher in the Southeastern United States [26] and amongst urban secondary school teachers in Namibia [35]. As previous research explains, the beginner teacher is vulnerable to burnout, due to the fact that new beginners tend to be idealistic and often very eager to perform professionally [36], when they fail to reach their students, they feel undervalued and unappreciated in terms of their performance. They feel more anxious and inadequate and become vulnerable to burnout [37].

\section{Burnout and Workload}

This study found workload based on hours of teaching to be significantly related to burnout. The results of this study are consistent with previous studies that concluded workload is associated with teacher burnout in Namibia [35], amongst the administrative staff of Kermanshah University of Medical Sciences of Iran [6] and amongst science teachers in the district of Jhajjar in Northern India [27]. The results of this study are also consistent with burnout studies in other 
professions, such as Jalili et al [38] which concluded that workload was a significant predictor of burnout among Iranian emergency medicine practices.

TABLE I. Characteristics of Special School Teachers in SAMARinda, INDONESIA (N=90) AND Association BetweEn ITS VARIABLES AND BURNOUT PREVALENCE

\begin{tabular}{|c|c|c|c|c|c|}
\hline Variables & Number & $(\%)$ & Mean & $\mathrm{SD}$ & Correlation $(\mathrm{p})$ \\
\hline Gender & & & 1.77 & 0.4 & $0.802^{*}$ \\
\hline Man & 19 & 21.1 & & & \\
\hline Women & 71 & 78.9 & & & \\
\hline Marital status & & & 1.21 & 0.4 & $0.034 *$ \\
\hline Married & 73 & 81.1 & & & \\
\hline Not married & 14 & 15.5 & & & \\
\hline Ever been married & 3 & 3.3 & & & \\
\hline Age (years) & & & 41.1 & 9.9 & $0.096 * *$ \\
\hline $19-27$ & 14 & 15.5 & & & \\
\hline $28-36$ & 14 & 15.5 & & & \\
\hline $37-45$ & 22 & 24.4 & & & \\
\hline $46-54$ & 34 & 37.7 & & & \\
\hline $55-63$ & 6 & $6.6)$ & & & \\
\hline Education background & & & 1.73 & 0.4 & $0.428 *$ \\
\hline Special school teacher education & 19 & 21.2 & & & \\
\hline Non special school teacher education & 71 & 78.8 & & & \\
\hline Working experience (years) & & & 11.78 & 7.6 & $0.023 * *$ \\
\hline $0-8$ & 31 & 34.4 & & & \\
\hline$>8-16$ & 29 & 32.2 & & & \\
\hline$>16-24$ & 26 & 28.9 & & & \\
\hline$>24-33$ & 4 & 4.5 & & & \\
\hline Employment status & & & 1.18 & 0.7 & $0.598 *$ \\
\hline Contract & 18 & 20 & & & \\
\hline Permanent & 72 & 80 & & & \\
\hline Hours of teaching (hour/week) & & & 24.4 & 2.3 & $0.044 * *$ \\
\hline 18 hours & 1 & 1.1 & & & \\
\hline 20 hours & 1 & 1.1 & & & \\
\hline 24 hours & 81 & 90 & & & \\
\hline 30 hours & 5 & 5.5 & & & \\
\hline 36 hours & 2 & 2.2 & & & \\
\hline Job Stress & & & 20.2 & 13.45 & $0.004 * *$ \\
\hline Normal & 62 & 68.9 & & & \\
\hline Minor & 27 & 20.1 & & & \\
\hline Severe & 1 & 1.1 & & & \\
\hline Self-concept & & & 383.1 & 28.10 & $0.010^{* *}$ \\
\hline Positive & 45 & 50 & & & \\
\hline Negative & 45 & 50 & & & \\
\hline Burnout & & & 45.7 & 4.84 & \\
\hline Low & 24 & 26.7 & & & \\
\hline Medium & 66 & 73.3 & & & \\
\hline
\end{tabular}

*) Chi square, $* *$ ) Pearson correlation

TABLE II. BURNOUT DIMENSION OF SPECIAL SCHOOL TEACHERS (N=90)

\begin{tabular}{cccccc}
\hline No & Burnout Dimension & Number of items & Mean & SD & Min \\
\hline 1 & Emotional Exhaustion & $1,2,7,8,14,15,19,20,22$ & 19.05 & 2.70 & 9 \\
2 & Depersonalization & $3,4,9,10,16$ & 10.80 & 1.43 & 5 \\
3 & Personal Accomplishment & $5,6,11,12,13,17,18,21$ & 15.84 & 1.94 & 8 \\
\hline
\end{tabular}

\section{E. Burnout and Job Stress}

The results showed only 27 teachers $(20.1 \%)$ experienced light work stress, but statistically, job stress is significantly related to burnout. These results are consistent with some previous studies concluding that job stress is the direct cause of burnout in science teacher in the district of Jhajjar [27], job stress is significantly related to burnout in secondary teachers in Southeastern United States [26]. In other professions such as nursing, job stress has also been shown to be associated with burnout. The job stress of hospital nurses was significantly related to burnout in Gauteng Province of South Africa [39], and significant positive relationship between job stress and emotional exhaustion, depersonalization, and personal accomplishmen [40]t.

\section{F. Burnout and Self-concept}


We found equal degrees of positive self-concept and negative self-concept amongst special school teachers, and data analysis proved the self-concept of special school teachers to be significantly correlated with burnout. The results of this study reinforce previous studies that concluded self-esteem as a strong predictor of teacher burnout across Iranian and Turkish teachers [41], and self-concept is significantly related to burnout and may be used as a predictor of the incidence of burnout in elementary teachers in Israel [42]. In other professions such as nurses in Nigeria, self-concept has also been shown to be related to burnout [43].

Self-concept is rarely seen as a very important factor of teacher $\mathrm{s}$ professional activities, although it could be expected it is related to both internal and external factors of effective teaching [44]. Teachers with a positive self-concept are happier, more productive and more effective in discharging their duties as teachers and thus become less inclined to burnout [14]. Other conclusions prove selfconcept plays an important role in events, feelings, and behavior; teachers with a positive self-concept will experience less of the symptoms of stress and burnout. Teachers with negative self-concept were found to perceive and assess events in such a way that they will feel dissatisfied with their work [45].

\section{CONCLUSIONS}

All the special school teachers in Samarinda city experienced burnout, consisting $73.3 \%$ of medium level and $26.7 \%$ of low-level. Marital status ( $p=0.03)$, working experience $(\mathrm{p}=0.023)$, hours of teaching $(\mathrm{p}=0.044)$, job stress $(\mathrm{p}=0.004)$ and self-concept $(\mathrm{p}=0.010)$ were significantly associated with burnout. Meanwhile, gender $(\mathrm{p}=0.802)$, age $(p=0.096)$ and employment status of teacher $(p=0.598)$ are not related to burnout. To manage burnout in special school teachers, the school is advised to reduce the teacher's workload, make efforts to improve teacher self-concept and provide training for beginner teachers on educating students with special needs. For further research, it is advisable to further explore the factors causing job stress on the teacher so that the appropriate alternative can be found

\section{ACKNOWLEDGMENT}

The authors are very grateful to all the teachers of special school who are participated in this study.

\section{REFERENCES}

[1] M. Gorji, "The Effect of Job Burnout Dimension o n Employees " Performance," Int. J. Soc. Sci. Humanit., vol. 1, no. 4, pp. 243-246, 2011.

[2] A. Khan, I. M. Shah, S. Khan, and S. Gul, "Teachers' stress, performance \& resources the moderating effects of resources on stress \& performance.," Int. Rev. Soc. Sci. Humanit., vol. 2, no. 2, pp. 21-29, 2012.

[3] C. Maslach and S. E. Jackson, "The role of sex and family variables in burnout," Sex Roles, vol. 12, no. 7-8, pp. 837-851, 1985.

[4] S.-H. Kwag and M.-H. Kim, "The Study On The Effects Of Organizational Members Job Burnout," J. Bus. Econ. Res., vol. 7, no. 7, pp. 63-78, 2011.

[5] R. G. Enache, "Burnout Syndrome and Work Accidents," Procedia Soc. Behav. Sci., vol. 78, pp. 170-174, 2013.

[6] M. ZIAEI, H. YARMOHAMMADI, M. MORADI, and M.
KHANDAN, "International Journal of Occupational Hygiene IJOH," Int. J. Occup. Hyg., vol. 7, no. 2, pp. 53-60, 2015.

[7] J. Ogresta, S. Rusac, and L. Zorec, "Relation Between Burnout Syndrome and Job Satisfaction Among Mental Health Workers," Croat Med J., vol. 49, pp. 364-374, 2008.

[8] M. Goswami, "A Study of Burnout of Secondary School Teachers in Relation to their Job Satisfaction," IOSR J. Humanit. Soc. Sci., vol. 10, no. 1, pp. 18-26, 2013.

[9] P. R. Gil-Monte, M. S. Carlotto, and S. G. Câmara, "Prevalence of burnout in a sample of Brazilian teachers," Eur. J. Psychiatry, vol. 25, no. 4, pp. 205-212, 2011.

[10] J. Al-Asadi, S. Khalaf, A. Al-Waaly, A. Abed, and S. Shami, "Burnout among primary school teachers in Iraq: Prevalence and risk factors," East. Mediterr. Heal. J., vol. 24, no. 3, pp. 262-268, 2018.

[11] S. Mousavy, N. S. Thomas, J. Mukundan, and V. Nimehchisalem, "Burnout among low and high experienced teachers," Int. J. Appl. Linguist. English Lit., vol. 1, no. 4, pp. 24-29, 2012.

[12] B. Adekola, "Work Burnout Experience among University Non Teaching Staff: A Gender Approach," Int. J. Acad. Res. Bus. Soc. Sci., vol. 2, no. 1, pp. 128-135, 2012.

[13] H. Ipek, A. Akcay, S. Atay, G. Berber, T. Karalik, and T. Yilmaz, "The Relationship Between Occupational Stress And Teacher SelfEfficacy: A Study With EFL Instructors," Anadolu Üniversitesi Eğitim Bilim. Enstitüsü Derg., vol. 8, no. 1, pp. 126-150, 2018.

[14] A. Z. Rad and R. Nasir, "Burnout and career self concept among teachers in Mashhad, Iran," Procedia - Soc. Behav. Sci., vol. 7, no. C, pp. 464-469, 2010.

[15] A. Hosseini Fatemi and R. Raoufi, "Burnout and teaching style among Iranian English language educators in public schools and private institutes: A cross-comparison study," Int. J. Res. Stud. Lang. Learn., vol. 1, no. 1, 2014.

[16] L. Rey, N. Extremera, and M. Pena, "Emotional competence relating to perceived stress and burnout in Spanish teachers: a mediator model," Peer J, vol. 2087, pp. 1-14, 2016

[17] J. Manuel, O. López, C. C. Bolaño, M. José, and S. Mariño, "Exploring Stress, Burnout, and Job Dissatisfaction in Secondary School Teachers," Int. J. Psychol. Psychol. Ther., vol. 10, no. 1, pp. 107-123, 2010

[18] R. L. Berry, "Special education teacher burnout: the effects of efficacy expectations and perceptions of job responsibilities," Western Washington, 2011.

[19] D. W. Emery and B. Vandenberg, "SPECIAL EDUCATION TEACHER BURNOUT AND ACT," Int. J. Spec. Educ., vol. 25, no. 3, pp. 119-131, 2010.

[20] J. J. Tejada and J. R. B. Punzalan, "On the Misuse of Slovin ' Formula," Philipp. Stat., vol. 61, no. 1, pp. 129-136, 2012.

[21] R. Pandey and M. R. Verma, "SAMPLES ALLOCATION IN DIFFERENT STRATA FOR IMPACT," Rev. Bras. Biom, vol. 26, no. 4, pp. 103-112, 2008.

[22] C. Maslach and S. E. Jackson, "The measurement of experienced burnout," J. Occup. Behav., vol. 2, no. April 1980, pp. 99-113, 1981.

[23] S. Naz and S. Gul, "Translation and Validation of Tennessee Self Concept Scale," J. Behav. Sci., vol. 26, no. 1, p. 130, 2016.

[24] S. . Lovibond and P. . Lovibond, Manual for the depression anxiety stress scales. Sydney, Australia: Psychology Foundation of Australia, 1996.

[25] Caruso AL, Giammanco, and Gitto L, "Burnout Experience Among Teachers: a Case Study," Mediterr. J. Clin. Psychol. MJCP ISSN, vol. 3, pp. 2282-1619, 2014.

[26] M. H. Fisher, "Factors Influencing Stress , Burnout, and Retention of Secondary Teachers," Curr. Issues Educ., vol. 14, no. 1, 2011

[27] R. Deswal and Savita, "Burnout in Science Teachers," Int. J. Indian Psychol., vol. 2, no. 4, pp. 20-27, 2015.

[28] N. Tsigilis, D. Ph, and E. Zournatzi, "Burnout among physical education teachers in primary and secondary schools," Int. J. Humanit. Soc. Sci., vol. 1, no. 7, pp. 53-58, 2011.

[29] S. Arora and V. Nagra, "occupational stress and health among teacher educators," Int. J. Adv. Res. Manag. Soc. Sci., vol. 2, no. 8, pp. 1-13, 2013.

[30] V. J. Llorent and I. Ruiz-Calzado, "Burnout and its relation to sociodemographic variables among education professionals working with people with disabilities in Córdoba (Spain)," Cienc. e Saude Coletiva, vol. 21, no. 10, pp. 3287-3295, 2016.

[31] J. Ogden, Health Psychology. A Textbook, 3rd ed. England: Open University Press, 2004 
[32] A. Asgari, "SOCIAL SCIENCES \& HUMANITIES The Effects of Gender and Marital Status on Burnout of English Teachers in Iran," Pertanika J. Soc. Sci. Hum. 20, vol. 20, no. 3, pp. 635-644, 2012.

[33] K. Sadeghi and S. Khezrlou, "Burnout among English Language Teachers in Iran: Do Socio-demographic Characteristics Matter?," Procedia - Soc. Behav. Sci., vol. 98, pp. 1590-1598, 2014.

[34] Si. S. Farshi and F. Omranzadeh, "The Effect of Gender, Education Level, and Marital Status on Iranian EFL Teachers ' Burnout Level," Int. J. Appl. Linguist. English Lit., vol. 3, no. 5, 2014.

[35] D. Louw, E. George, and K. Esterhuyse, "Burnout amongst urban secondary school teachers in Namibia Research design," SA J. Ind. Psychol., vol. 37, no. 1, pp. 1-7, 2011.

[36] S. Gibbs and A. Miller, "Teachers resilience and well-being: A role for educational psychology," Teach. Teach. Theory Pract., vol. 20, no. 5, pp. 609-621, 2014.

[37] P. Tynjälä and H. L. T. Heikkinen, "Beginning teachers' transition from pre-service education to working life: Theoretical perspectives and best practices," Zeitschrift fur Erziehungswiss., vol. 14, no. 1, pp. $11-33,2011$.

[38] M. Jalili, G. Sadeghipour Roodsari, and A. Bassir Nia, "Burnout and associated factors among iranian emergency medicine practitioners," Iran. J. Public Health, vol. 42, no. 9, pp. 1034-1042, 2013.

[39] N. Khamisa, B. Oldenburg, K. Peltzer, and D. Ilic, "Work related stress, burnout, job satisfaction and general health of nurses," Int. J. Environ. Res. Public Health, vol. 12, no. 1, pp. 652-666, 2015.

[40] M. R. Abarghouei, M. H. Sorbi, M. Abarghouei, R. Bidaki, B. Sciences, and S. Sadoughi, "Electronic Physician ( ISSN : 2008-5842 )," Electron. Physician, vol. 8, no. 7, pp. 2625-2632, 2016.

[41] E. Khezerlou, "Language Teaching Research Professional self-esteem as a predictor of teacher burnout across Iranian and Turkish EFL teachers," Iran. J. Lang. Teach. Res., vol. 5, no. 1, pp. 113-130, 2017.

[42] I. A. Friedman and B. A. Farber, "Professional Self-Concept as a Predictor of Teacher Burnout," J. Educ. Res., vol. 86, no. 1, pp. 2835, 1992.

[43] C. E. Nwafor, E. U. Immanel, and H. Obi-nwosu, "Does nurses ' selfconcept mediate the relationship between job satisfaction and burnout among Nigerian nurses," Int. J. AFRICA Nurs. Sci., vol. 3, pp. 71-75, 2015.

[44] B. Zlatković, S. Stojiljković, G. Djigić, and J. Todorović, "Selfconcept and Teachers' Professional Roles," Procedia - Soc. Behav. Sci., vol. 69, pp. 377-384, 2012.

[45] A. Villa and E. Calvete, "Development of The Teachers Self-Concept Evaluation Scale and Its Relation to Burnout," Stud. Educ. Eval., vol. 27, pp. 239-255, 2001. 